\title{
La población mexicana de 2011: lo que no ocurrió*
}

\section{Manuel Ordorica**}

Hace una década, cuando se cumplían 15 años de la fundación de la Sociedad Mexicana de Demografía (Somede), presenté una ponencia con el titulo: "La población mexicana del 2011: demografía ficción". En esa ocasión tuve la oportunidad de compartir mis reflexiones con los ex presidentes de la Somede, entre los que se encontraban Gustavo Cabrera y José Gómez de León, dos colegas a quienes recordamos por su trabajo en la demografía. También tenemos en nuestro pensamiento a Vania Salles, a Raúl Benítez Zenteno y a Sergio Camposortega, queridos profesores de esta disciplina. Todos ellos nos acompañan en esta reunión.

El 23 de septiembre de 1996 decía yo que México tendría 110 millones de personas en el año 2011. Es muy probable que no lleguemos a ese número. Serán alrededor de 2 millones menos de habitantes como resultado de una mayor migración internacional. Las hipótesis que planteamos al final del siglo pasado respecto a este componente estuvieron por debajo de lo estimado. Alcanzamos los 100 millones de mexicanos en 2002. Decía también que en 2011 se llegaría a 1\% anual; sin embargo alcanzamos la cifra de $1 \%$ en el crecimiento total en 2003 , pero con un crecimiento natural de 1.6\%. La meta que se planteó en 1977 para el año 2000 fue en el crecimiento natural. En 2000 este indicador llegó a 1.9\% anual, lejos de lo que se había supuesto. Lo que no pudieron hacer los programas de planificación familiar lo hizo la migración internacional. Salen hoy 580 mil personas por año, de ahí que la migración a Estados Unidos haya sido la válvula de escape a la situación de desigualdad que vive el país. La esperanza de vida al nacer se ha mantenido en poco más de 74 años y ha permanecido prácticamente invariable en el último quinquenio. Se requerirían grandes esfuerzos para alcanzar los 80 años que decía yo que tendríamos en 2011, pues habría que incrementar seis años la esperanza de vida al nacer y sobre todo reducir la mortalidad en la infancia, en la niñez y en las edades avanzadas. Respecto a los niveles de fecundidad, México se encuentra hoy prácticamente en el de reemplazo 2.2, y es posible que para 2011 se ubique por debajo de ese nivel.

* Discurso presentado en la Reunión Nacional de Demografía celebrada en Guadalajara del 6 al 9 de septiembre de 2006 .

** El Colegio de México. Correo electrónico: mordori@colmex.mx.

ESTUDIOS DEMOGRÁFICOS Y URBANOS, VOL. 22, NÚM. 1 (64), PP. 213-218 
La población de 0 a 15 años está reduciéndose, la de 15 a 64 años crece moderadamente, y la de 65 años y más crece aceleradamente. México se encuentra en un proceso acelerado de envejecimiento de su población, el cual es irreversible.

Para entender esta nueva demografía los expertos en población tendremos que incursionar en nuevos campos, como la biología y la gerontología, entre otros. Resulta de especial importancia saber por qué Jeanne Calment vivió 122 años. ¿Por qué la tortuga marina puede llegar a vivir 150 años? Me parece que los demógrafos debemos enriquecer nuestras investigaciones en campos que ayuden a entender el proceso de envejecimiento. Por ejemplo, el síndrome de Down es una enfermedad que se vincula al mapa cromosómico. ¿Por qué estas personas envejecen aceleradamente?

Un tema que en estos años se ha estudiado es el relativo a la mortalidad a partir de los 65 años. Las principales causas de muerte en esas edades son la diabetes, los infartos, las enfermedades pulmonares, la insuficiencia cardiaca y la neumonía, que representan alrededor de la tercera parte de las muertes en estas edades. Muchas de ellas son defunciones prevenibles.

El tipo de familia también cambiará. Hoy observamos que en las familias nucleares ampliadas pueden convivir hasta cuatro generaciones: hijo, padre, abuelo, y bisabuelo. Esto puede ser relevante en el análisis de la dinámica demográfica futura del país. El tiempo de convivencia de los padres con sus hijos se extiende en muchos casos por más de medio siglo, cuando hace un siglo sólo convivían unas dos o tres décadas. Los que nazcan ahora podrán aprovechar la experiencia de sus padres, abuelos y bisabuelos.

Como se sabe, las mujeres son más longevas que los hombres. Precisamente por esto y porque a edades avanzadas suele haber más padecimientos y carencias de recursos, son más las mujeres pobres y enfermas, lo cual acarrea para ellas una doble discriminación; muchas no tienen seguridad social. Problemas como éste estrecharán más las relaciones científicas entre los demógrafos y los actuarios, quienes deberán tomar en cuenta estas situaciones para diseñar nuevos esquemas de jubilación que tengan como punto de apoyo a las mujeres, quienes suelen vivir solas por largos periodos. Deberá estudiarse la posibilidad de que los sistemas de seguridad social entrelacen a distintas generaciones. Considero, además, que debería preverse el incremento de la edad de retiro a los 75 años, puesto que en la actualidad la salida de la actividad económica corresponde a una inferior esperanza de vida al nacer. 
Nos encontramos en una nueva etapa de la transición epidemiológica y demográfica como consecuencia de la creación de nuevas generaciones de antibióticos para abatir las enfermedades bacterianas y virales. En los próximos años habrá un control del envejecimiento y la senilidad, se curarán la hipertensión, y la trombosis, y seguramente se avanzará en el tratamiento del cáncer. Asimismo se crearán nuevos métodos de anticoncepción para hombres. Con estos avances científicos se podría esperar un incremento sustancial de la esperanza de vida a cerca de 90 años. Si esta cifra se llegara a alcanzar, nuestra sociedad sufriría grandes modificaciones; habría vidas largas y con buena salud en sus últimas etapas. La juventud, que ahora abarca de 0 a 25 años, sería de 0 a 35 años; los adultos jóvenes de entre 25 y 45 años vivirían esta etapa de los 35 a los 55; las edades medias que hoy van de 45 a 65 años, abarcarían de los 55 a los 75 , y los adultos mayores entre los 65 y los 85 vivirían este periodo de los 75 a los 95 o quizás hasta los 100 años. Este aumento en la esperanza de vida propiciará un incremento aún mayor de la tasa de crecimiento demográfico, sobre todo de la población de edad avanzada.

Debido al éxito que ha obtenido la política de población en los últimos años del siglo Xx, en la regulación de la natalidad, y a que se redujeron las brechas en los niveles de fecundidad por clase social y regiones, esta variable pasó a un segundo término en la explicación de la dinámica poblacional. El que se hayan incorporado temas de demografía, sexualidad y familia en los programas de educación primaria y secundaria ha favorecido la conciencia sobre los aspectos sociodemográficos. Ahora resulta más interesante analizar a las parejas con niveles de reproducción elevados. Es de especial interés la ampliación del periodo fértil, lo que provocará que la cúspide de la curva de fecundidad se recorra a edades más avanzadas.

La mortalidad se deberá estudiar principalmente en los primeros días de vida y en las edades más avanzadas, pues en las restantes es muy reducida. Seguramente pronto se curarán el sida y el cáncer. El perfeccionamiento de la amniocentesis permitirá anticiparse en la detección de posibles anomalías congénitas.

Debido a las diferencias económicas que se observan entre regiones y grupos sociales, la migración continúa siendo un tema de gran interés para los investigadores. Los estudios se deberán centrar en el análisis de la movilidad hacia las fronteras, las ciudades medias y las zonas costeras.

El Registro Nacional de Población y el Registro de Electores permiten observar los movimientos de orden demográfico y social de cada 
individuo. En el futuro convendrá usar más ciertas fuentes de información como las estadísticas vitales, y menos las encuestas. Además, los sistemas de información geográfica serán el instrumento clave para el futuro. La experiencia de la segunda mitad del siglo XX en materia de generación de información es que se realizó un gran número de encuestas que se analizaron poco.

Las aulas dejarán de ser el lugar de enseñanza. Los cursos se impartirán más desde la casa del profesor debido a los avances de la cibernética, por lo que será posible tener un control estricto del estudiante y de su aprendizaje. Seguramente en la Reunión Nacional e Internacional de Demografía que se realizará en el año 2020, la Somede tendrá invitados de varias partes del mundo, quienes presentarán sus ponencias desde sus respectivos países.

Los especialistas en población intensificarán su trabajo en la demografía de los negocios, en la demografía electoral, en las proyecciones de población a nivel microrregional. El futuro estará lleno de nuevos métodos estadísticos basados en modelos dinámicos, en geoestadística y en la teoría de procesos estocásticos. Un ejemplo de este tipo de métodos es la historia de eventos.

La Sociedad Mexicana de Demografía deberá perseguir los mismos objetivos para los que fue creada. Dirigida en ocasiones por funcionarios públicos y a veces por académicos, continuará siendo la conciencia crítica de los demógrafos. Se deberán organizar cursos de actualización. Muchos grupos de trabajo que antes se orientaban al estudio de la población en edades fértiles ahora se deberán centrar en temas tan relevantes como la salud en la vejez. La Sociedad Mexicana de Demografía está lista para ramificarse hacia esas áreas y continuar con su labor de mediación entre quien investiga y el que actúa. Sigue siendo un ámbito de reflexión aislado de presiones políticas e interesado en la realidad nacional.

\section{¿Cuáles son las oportunidades del demógrafo?}

Su labor es indispensable debido a la necesidad de diseñar políticas públicas con fundamento demográfico; a la conciencia creciente que en los medios de comunicación ha surgido respecto a los problemas de población; al surgimiento de nuevas temáticas sociodemográficas; a los nuevos problemas que acarrea para la investigación el envejecimiento de la población; a la realización de nuevas investigaciones, 
como en el caso de la demografía electoral para la redistritación y el análisis y la evaluación del padrón electoral; asimismo su contribución es necesaria para la planeación demográfica estatal; la posibilidad de trabajar en el sector privado en el campo de la demografía de los negocios; la utilización de técnicas modernas en el procesamiento de datos; el desarrollo tecnológico que puede enriquecer la educación y la docencia, como la emisión de videoconferencias y el uso de sistemas de información geográfica, entre otros aspectos.

\section{La oportunidad de hacer un balance}

Durante el decenio de los sesenta se realizaron en México los primeros modelos orientados a establecer relaciones entre el desarrollo y el crecimiento de la población; sin embargo tuvieron poco éxito en el avance del conocimiento. En los setenta, la experiencia obtenida en la investigación demográfica, junto con la información que se iba generando y la conciencia política alrededor de los problemas del crecimiento demográfico, llevó a la creación de instancias políticas que se encargaron de definir y ejecutar la política de población, por lo que muchos estudios se abocaron a la tarea de avanzar en la planeación demográfica. En los años ochenta hubo progresos en la discusión del papel de la población en la planificación del desarrollo; se hizo evidente la necesidad de enmarcar las políticas de población en el contexto histórico de la economía y la sociedad. Se buscaba integrar las políticas de población en la planeación del desarrollo. La moda de los modelos y el interés que las agencias internacionales pusieron en la integración de las políticas dirigieron la investigación demográfica. En los noventa se favoreció y se apoyó notablemente la investigación sobre la salud reproductiva y el género. Sin embargo, en la medida en que los niveles de fecundidad han continuado descendiendo hasta llegar casi al nivel del reemplazo, las agencias donantes seguramente habrán de canalizar sus apoyos hacia otros temas. El siglo XXI se inicia con el impulso a la vinculación entre la demografía y el ambiente. Los estudios de género se fortalecen. Pierde interés la política de población en lo referente a la regulación de la fecundidad. La migración internacional se convierte en la variable clave a estudiar. Lo concerniente a la jubilación se escucha en todos los ámbitos.

En el futuro, el demógrafo deberá ampliar más su curiosidad hacia trabajos realizados por otras disciplinas. La demografía tiene que in- 
tensificar su cooperación con la estadística, la matemática, la economía, la sociología, la antropología y la biología, entre otras ciencias.

Los temas relacionados con el empleo y la pobreza revisten una alta prioridad para los demógrafos. Para el estudio de la población marginal de los medios urbanos y rurales es precisa la cooperación entre los demógrafos, los sociólogos y los economistas. Resulta de especial importancia el estudio de la demografía étnica.

Las técnicas de intercambio de información como el internet posibilitan el envío de mensajes que permiten diálogos interactivos sobre las experiencias de investigadores que se encuentran en países alejados; esto seguramente despertará curiosidad y estimulará la competencia y la reflexión sobre el significado de la investigación.

Finalmente, es papel del demógrafo convencer a los responsables de la acción política y al público de la importancia del tema poblacional. Así el campo de la educación en población estimulará una mayor conciencia sobre los aspectos sociodemográficos.

Gran parte de lo aquí planteado es todavía en México ciencia ficción. El Registro Nacional de Población sigue como hace 30 años. Las estadísticas vitales no han mejorado. Son muchas las fuentes de información que no hemos evaluado. La concentración de la población se parece a la de hace varios años. La generación de datos le ganó la carrera al análisis de la información. Hemos llegado al reemplazo y la familia pequeña no vive mejor. Hay millones de pobres. Como decía Gustavo Cabrera, la política demográfica ya cumplió, ahora le falta cumplir a la política de desarrollo. 